\title{
Changes in cardiac structure and function with aging
}

\author{
Tanushree Agrawal, Sherif F. Nagueh \\ Department of Cardiology, Methodist DeBakey Heart and Vascular Center, Houston, TX 77030, USA.
}

Correspondence to: Dr. Sherif F. Nagueh, Department of Cardiology, Methodist DeBakey Heart and Vascular Center, 6550

Fannin St, Suite 1801, Houston, TX 77030, USA. E-mail: snagueh@houstonmethodist.org

How to cite this article: Agrawal T, Nagueh SF. Changes in cardiac structure and function with aging. J Cardiovasc Aging

2022;2:13. https://dx.doi.org/10.20517/jca.2021.40

Received: 20 Dec 2021 First Decision: 29 Dec 2021 Revised: 3 Jan 2022 Accepted: 3 Jan 2022 Published: 12 Jan 2022

Academic Editor: Ali J. Marian Copy Editor: Xi-Jun Chen Production Editor: Xi-Jun Chen

\begin{abstract}
Aging is associated with progressive changes in cardiac structure and function. The prevalence of cardiovascular risk factors and disease also increases profoundly with advancing age. Therefore, understanding the spectrum of physiological changes in the aging heart is crucial for the identification and risk stratification of cardiovascular disease. In this review, we discuss echocardiographic features of age-related cardiac remodeling.
\end{abstract}

Keywords: Aging, cardiovascular imaging, echocardiography, systolic, diastolic

\section{INTRODUCTION}

Cardiovascular disease is the leading cause of mortality worldwide ${ }^{[1]}$. Aging is associated with dynamic, incremental changes in cardiac structure and function. The prevalence of cardiovascular risk factors and disease also rises exponentially with age. Enhanced understanding of the normally expected changes with healthy aging is crucial for the identification of pathology, risk stratification, and management.

Autopsy-based studies are inherently limited by the inability to distinguish the effects of normal aging from the primary disease or comorbid conditions that led to death ${ }^{[2]}$. Non-invasive cardiovascular imaging offers the unique opportunity to recruit healthy participants and study age-related cardiac remodeling in a longitudinal fashion. Due to widespread availability and low-cost, echocardiography represents the ideal 
imaging modality for epidemiological study of age-related changes in cardiac structure and function. In this review, we discuss age-related changes in cardiac structure and function, particularly the insights gained from population-based echocardiographic studies.

\section{LEFT VENTRICULAR STRUCTURE}

Linear measurements (left ventricular wall thickness, left ventricular mass, left ventricular enddiastolic diameter, left ventricular end-systolic diameter, and left ventricular-end diastolic length)

Early cross-sectional studies based on M-mode echocardiography first showed that advanced age was associated with increased left ventricular (LV) wall thickness. In a study of 136 adult participants without clinically apparent cardiovascular disease, elderly individuals (> 70 years) were found to have higher LV septal wall thickness and LV posterior wall thickness ${ }^{[3]}$. Similarly, a cross-sectional analysis of 4976 participants from the Framingham Heart Study showed a strong association between increasing age and LV hypertrophy; this association was independent of hypertension, coronary artery disease, valvular heart disease, and obesity ${ }^{[4]}$. These studies provided valuable insights about age-related changes in cardiac structure; however certain caveats should be considered. First, the findings may have been confounded because the analysis was limited to healthy survivors who were recruited at the time of the study. Second, the cross-sectional nature of these studies precluded the establishment of a cause-and-effect relationship between aging and the observed changes.

Prospective longitudinal studies of cardiac imaging in healthy participants would be ideally suited to resolving these issues. In a prospective evaluation of 4217 Framingham study participants over a 16-year follow-up period, LV wall thickness and cavity dimensions were measured by M-mode echocardiography. LV mass was calculated from linear measurements using the Devereux and Reichek cube formula: 0.8 [1.04 (LV end-diastolic internal dimension + LV septal wall thickness + LV posterior wall thickness) $)^{3}$ - (LV enddiastolic internal dimension $\left.)^{3}\right]+0.6^{[5]}$. Each participant underwent up to 4 serial routine echocardiographic studies. Advancing age was associated with the increase in LV mass; this age-related increase in LV mass was accelerated in individuals with a higher burden of cardiovascular risk factors ${ }^{[6]}$. Although LV mass is a well-established measurement with prognostic implications for cardiovascular risk, tracking cardiac remodeling using LV mass has certain limitations. First, LV mass is a composite variable derived from multiple individual measurements of LV structure (wall thickness and cavity dimensions). Therefore, changes in LV mass over time do not describe the relative changes in LV wall thickness and cavity dimensions. Second, errors in linear measurements can be magnified given the expression used to calculate LV mass, and therefore could lead to significant inaccuracy in the estimation of LV mass. Third, the formula for estimation of LV mass relies on geometric assumptions about LV shape, and these assumptions do not hold in asymmetric LV hypertrophy.

In order to define the specific components of age-related cardiac remodeling, Cheng et al. ${ }^{[7]}$ conducted a prospective study of 4062 Framingham Heart study participants over a 16-year follow-up period. Each individual participant underwent up to 4 serial routine echocardiographic examinations. The authors evaluated M-mode guided echocardiographic measurements of LV wall thickness, LV end-diastolic diameter, and LV end-systolic diameter. Advancing age was associated with increasing LV wall thickness and decreasing LV cavity size (end-diastolic and end-systolic dimensions).

Autopsy studies have revealed that aging is associated with progressive attrition of myocyte numbers and hypertrophy of the remaining myocytes ${ }^{[8]}$. Therefore, the observed increase in LV wall thickness can be explained by hypertrophy of existing cells as well as deposition of interstitial connective tissue rather than the addition of new myocytes. 
LV end-diastolic length (LVEDL), defined as the distance from the mitral annulus to LV apex, serves as a useful marker of LV sphericity or overall shape. Two studies to date have evaluated the impact of aging on LV length assessed by echocardiography. Kaku et al. ${ }^{[9]}$ evaluated LV length using real-time threedimensional echocardiography (3DE) in 280 healthy participants. They found that LVEDL decreased with age after 40 years. Similarly, in a study of 1266 healthy individuals, LVEDL was evaluated from twodimensional echocardiography $(2 \mathrm{DE})$. The investigators found that increasing age was associated with shorter LVEDL ${ }^{[10]}$. These concordant results suggest that with advancing age, the LV assumes a more spherical shape.

\section{Volumetric measurements}

The advent of $2 \mathrm{DE}$ and $3 \mathrm{DE}$ has allowed volumetric LV measurements with and without geometric assumptions, resulting in higher accuracy and reproducibility in comparison to linear measurements. Large cohort studies of healthy participants have provided normative reference values for $2 \mathrm{DE}$ and $3 \mathrm{DE}$ based LV chamber quantification, and these have been incorporated into the American Society of Echocardiography (ASE) guidelines ${ }^{[1-13]}$. However, there are no longitudinal studies evaluating the evolution of $2 \mathrm{DE}$ and $3 \mathrm{DE}$ derived measures of cardiac volumes over time with aging. Here, we discuss some notable findings regarding age-related cardiac remodeling from available data.

With respect to 2DE, the 2015 ASE guidelines for chamber quantification, the writing group extracted data from seven databases to provide normative reference values for $2 \mathrm{DE}$ derived LV volumes. On multivariable analysis, age was an independent predictor of LV end-diastolic volume (LVEDV), and LV end-systolic volume (LVESV). Increasing age was associated with a decrease in LVEDV and LVESV ${ }^{[13]}$.

The Normal Reference Ranges for Echocardiography study (NORRE) was a large-multicenter collaboration across 22 institutions for comprehensive echocardiographic evaluation of healthy volunteers ${ }^{[14]}$. An analysis of 734 participants showed that increasing age was associated with a decrease in LVEDV and LVESV, as well as indexed values (to body surface area) for these measurements (LVEDVi, LVESVi) ${ }^{[12]}$. Likewise, Daimon et al. ${ }^{[15]}$ evaluated 700 healthy Japanese individuals from the Japan Ambulatory Blood Pressure Monitoring Prospective study (JAMP); they reported inverse correlations of LVEDVi and LVESVi with age amongst men and women.

For 3DE, a study of 978 healthy participants from the London Life Sciences Prospective Population study; found that LVEDVi and LVESVi decreased with age amongst men and women ${ }^{[11]}$. Fukuda et al ${ }^{[16]}$ studied 410 healthy Japanese participants from the JAMP 3D study and found that increased age was associated with a decrease in LVEDV, LVEDVi, LVESV, and LVESVi. Further, an analysis of the NORRE study included 440 participants with 3D assessment. The authors found that LVEDV, LVEDVi, LVESV, and LVESVi all decreased with increasing age amongst men and women ${ }^{[17]}$. The progressive increase in LV chamber stiffness with age accounts for the decrease in LV volumes with aging ${ }^{[18]}$.

In summary, based on the available evidence, we can draw the following conclusions about age-related LV remodeling [Table 1]: LV wall thickness increases with advancing age, linear LV cavity dimensions (LV end-diastolic diameter, LV-end-systolic diameter as well as LV end-diastolic length) decrease with age, and $\mathrm{LV}$ volumes at end-diastole and end-systole decrease with age.

\section{LEFT ATRIAL VOLUME}

Left atrial enlargement is a marker of chronically elevated left atrial pressure, and serves as a robust prognostic marker for several cardiovascular diseases. Therefore, understanding the evolution of left atrial 
Table 1. Summary of studies showing changes in left ventricular structure with age

\begin{tabular}{|c|c|c|c|c|}
\hline Study & $\begin{array}{l}\text { Sample size } \\
(n)\end{array}$ & Study population & $\begin{array}{l}\text { Echocardiographic } \\
\text { modality }\end{array}$ & Key findings \\
\hline $\begin{array}{l}\text { Gardin et al. }{ }^{[3]} \\
\text { (1979) }\end{array}$ & 136 & Healthy adults; age range $20-97$ years & M-mode & LV septal wall thickness and LV posterior wall thickness increase with age \\
\hline $\begin{array}{l}\text { Levy et al. }{ }^{[4]} \\
(1988)\end{array}$ & 4976 & Framingham Heart study; age range $17-90$ years & M-mode & Increasing age was associated with LV hypertrophy \\
\hline $\begin{array}{l}\text { Lieb et al. } \\
(2009)\end{array}$ & 4217 & Framingham Heart study & M-mode & Increasing age was associated with increase in LV mass \\
\hline $\begin{array}{l}\text { Cheng et al. }{ }^{[7]} \\
(2010)\end{array}$ & 4062 & Framingham Heart study & M-mode & $\begin{array}{l}\text { Increasing age was associated with increasing LV wall thickness and decreasing LV cavity } \\
\text { size (end-diastolic and end-systolic dimensions) }\end{array}$ \\
\hline $\begin{array}{l}\text { Kaku et al. }{ }^{[9]} \\
\text { (2011) }\end{array}$ & 280 & Healthy subjects; age range 1-88 years & $3 D E$ & LVEDL decreased with increasing age beyond 40 years \\
\hline $\begin{array}{l}\text { Støylen et al. } \\
(2016)\end{array}$ & 1266 & HUNT3 study & $2 \mathrm{DE}$ & Increasing age was associated with decrease in LVEDL \\
\hline $\begin{array}{l}\text { Lang et al. }{ }^{[13]} \\
(2015)\end{array}$ & 7 databases & $\begin{array}{l}\text { Asklepios (year } 0 \text { and year 10), Flemengho, CARDIA5 } \\
\text { and CARDIA2, Padua 3D Echo Normal, } \\
\text { and the Normal Reference Ranges for Echocardiography } \\
\text { study }\end{array}$ & $2 \mathrm{DE}$ & Increasing age was associated with decrease in LVEDV and LVSEV \\
\hline $\begin{array}{l}\text { Kou et al. }{ }^{[12]} \\
(2014)\end{array}$ & 734 & NORRE study & $2 \mathrm{DE}$ & $\begin{array}{l}\text { Increasing age was associated with decrease in LVEDV and LVESV, as well as indexed } \\
\text { values (to body surface area) for these measurements (LVEDVi, LVSEVi) }\end{array}$ \\
\hline $\begin{array}{l}\text { Daimon et al. } \\
(2008)\end{array}$ & 700 & JAMP study & $2 \mathrm{DE}$ & $\begin{array}{l}\text { Increasing age was associated with decrease in LVEDVi and LVESVi amongst men and } \\
\text { women }\end{array}$ \\
\hline $\begin{array}{l}\text { Chahal et al. } \\
\text { (2012) }\end{array}$ & 978 & LOLIPOP study & $3 D E$ & LVEDVi and LVESVi decreased with age amongst men and women \\
\hline $\begin{array}{l}\text { Fukuda et al. } \\
\text { (2012) }\end{array}$ & 410 & JAMP study & $3 \mathrm{DE}$ & Increasing age was associated with decrease in LVEDV, LVEDVi, LVESV and LVESVi \\
\hline $\begin{array}{l}\text { Bernard et al. }{ }^{[17]} \\
(2017)\end{array}$ & 440 & NORRE study & $3 \mathrm{DE}$ & $\begin{array}{l}\text { LVEDV, LVEDVi, LVESV, and LVESVi decreased with increasing age amongst men and } \\
\text { women }\end{array}$ \\
\hline
\end{tabular}

HUNT: Trøndelag Health Study; NORRE: Normal Reference Ranges for Echocardiography; JAMP: Japan Ambulatory Blood Pressure Monitoring Prospective; LOLIPOP: London Life Sciences Prospective Population; LV: left ventricle; LVEDL: left ventricular end diastolic length; LVEDV: left ventricular end diastolic volume; LVESV: left ventricular end systolic volume; LVEDVi: left ventricular end diastolic volume indexed to body surface area; LVESVi: left ventricular end systolic volume indexed to body surface area.

volume (LAV) with normal aging is important to identify pathological changes.

The World Alliance Societies of Echocardiography (WASE) study is an international multi-center cross-sectional study of healthy individuals. In a study of 1765 individuals, advancing age was associated with an increase in absolute as well as indexed LAV ${ }^{[19]}$. These data support the conclusion that the upper limit 
of normal LAV varies with age. Further research is needed to define age-specific thresholds for left atrial enlargement.

\section{RIGHT VENTRICULAR SIZE}

Due to the complex geometry of the right ventricle (RV), traditional echocardiographic assessment of RV anatomy is challenging. Therefore, there is an overall paucity of data regarding age-related changes in RV size and structure from traditional echocardiographic techniques. However, the recent advent of threedimensional echocardiography and cross-sectional imaging techniques such as cardiac magnetic resonance imaging (CMR) and cardiac computed tomography has allowed accurate assessment of RV size. In a multicenter study of 507 healthy volunteers, 3D echocardiography was used for the measurement of RV volumes. This study showed that older age was associated with smaller RV end-diastolic and end-systolic volumes ${ }^{[20]}$. Similarly, a retrospective study of 183 healthy participants comparing CMR-derived ventricular dimensions across different age groups showed that increasing age was associated with a decrease in RV end-diastolic and end-systolic volumes ${ }^{[21]}$.

\section{RIGHT ATRIAL VOLUME}

An analysis of 2008 healthy participants from the WASE study showed that there were no significant agerelated differences in $2 \mathrm{D}$ derived right atrial volume (RAV); however, $3 \mathrm{D}$ derived RAV showed a trend towards a slight decrease amongst elderly participants ${ }^{[22]}$. From this data, we can conclude that right atrial enlargement should not be disregarded as a mere component of physiologic aging. Common culprits to consider include tricuspid regurgitation, chronically elevated right ventricular filling pressures, and atrial fibrillation.

\section{SYSTOLIC FUNCTION}

Parameters for assessment of LV global systolic function include: fractional shortening, LV ejection fraction (LVEF), and global longitudinal strain (GLS).

In a cross-sectional study of 105 male individuals from the National Institute on Aging Volunteer Longitudinal Study Program, there was no age-related difference in fractional shortening amongst participants. This was one of the first studies to show that resting LV contractile function was preserved with advancing age ${ }^{[23]}$. Different studies have shown discordant results regarding the change in LVEF with aging. While some studies showed that LVEF increases with advancing age, others showed no significant age-related differences in $\operatorname{LVEF}^{[12,15,24,25]}$. Analysis of $2 \mathrm{D}$ derived LVEF from several population-based datasets showed that normal aging was not associated with any significant change in $\operatorname{LVEF}^{[13]}$.

In a study of 77 healthy volunteers, radionuclide angiocardiography was used to evaluate LVEF at rest and during exercise (upright bicycle). As noted in prior studies, global LV systolic function was not affected by age. However, exercise-induced LVEF augmentation was blunted amongst elderly participants (age $>70$

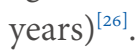

GLS measurement depends on several technical factors, and reported ranges of normal GLS values differ considerably between different vendors. In an individual patient meta-analysis of 8 studies comprising 2396 healthy participants, D'Elia et al. ${ }^{[27]}$ found that the absolute value of GLS was lower amongst elderly individuals (age $>60$ years) compared with younger individuals [20.0\% (CI: 18.4-21.9) vs. 21.0\% (CI: 19.422.9), $P<0.01]$. 
Hung et al. ${ }^{[25]}$ studied 1105 individuals without prevalent heart failure from the Atherosclerosis Risk in Communities study (ARIC). They evaluated LV global longitudinal strain, global circumferential strain, and torsion using 3DE. Older age was associated with a lower absolute value of GLS, higher global circumferential strain, and higher indices of torsion. This suggests that an increase in torsion and global circumferential strain compensate for age-related decline in GLS and therefore result in preserved LVEF with advancing age.

\section{DIASTOLIC FUNCTION}

Heart failure with preserved LV ejection fraction (HFpEF) accounts for approximately half of all cases with heart failure. One of the key abnormalities in HFpEF is LV diastolic dysfunction, and the prevalence of LV diastolic dysfunction increases significantly with age ${ }^{[28-31]}$. Aging itself is associated with changes in LV myocardial relaxation and LV chamber stiffness ${ }^{[18]}$. Of all the physiologic factors that impact LV diastolic function, age has been shown to be the strongest determinant ${ }^{[32,33]}$. Therefore, distinguishing LV diastolic dysfunction from normal age-related changes in the elderly is challenging.

Besides the morphologic assessment of the cardiac chambers' volumes and LV mass, the most important echocardiographic parameters for evaluation of LV diastolic function include pulse-Doppler flow profiles (transmitral and pulmonary venous flow), tissue Doppler imaging (TDI) mitral annular velocities, and pulmonary artery systolic pressure [Figures 1 and 2] ${ }^{[18]}$. Transmitral E/A ratio, and pulmonary vein peak systolic to peak diastolic velocity ratio are indices of early diastolic LV filling pressures that are most accurate in patients with LV systolic dysfunction and depressed LV EF ${ }^{[18]}$. Mitral annulus early diastolic velocity (e') is an index of LV relaxation, whereas E/e' ratio is an index of LV early diastolic pressures that can be applied in patients with normal as well as in patients with depressed LV EF ${ }^{[18]}$. Here, we discuss some of the notable studies that illustrated age-related changes in these parameters.

In a population-based prospective study of 1012 subjects from the Rochester Epidemiology Project, Munagala et al. ${ }^{[34]}$ studied LV diastolic parameters by Doppler echocardiography. Key findings are herein summarized. Aging was associated with decrease in early transmitral flow, early diastolic velocity (E), increase in atrial transmitral flow velocity (A), decrease in E/A ratio, and increase in E wave deceleration time. These changes have been attributed to the age-related slowing of myocardial relaxation ${ }^{[35]}$. For pulmonary vein flow velocities, aging is associated with increase in systolic flow velocity (S), decrease in diastolic flow velocity (D), and increase in ratio of systolic/diastolic flow velocity (S/D). Likewise, for mitral annular velocities, aging is associated with a decrease in early diastolic mitral annular velocity (e'), likely due to the slowing of myocardial relaxation. However, importantly, the difference in duration between mitral inflow A velocity and pulmonary venous $A_{R}$ velocity (time interval: $A_{R}-A$ ) does not change significantly with age. This is important as $A_{R}-A$ duration is an index of $L V$ end-diastolic pressure ${ }^{[18]}$.

The Doppler NORRE sub-study included 449 volunteers with no evidence of cardiac pathology on echocardiography. Participants were stratified by age into three categories (20-40 years, 40-60 years, and $\geq$ 60 years). Similar to prior studies, elderly individuals (age $\geq 60$ years) had lower E velocity, higher A velocity, lower E/A ratio, and longer E wave deceleration time. Tissue Doppler e' velocity decreased significantly with age in both genders. The E/e' ratio increased progressively with advancing age; however, the cut-off value of average E/e' remained $<15^{[36]}$.

In an analysis of 5801 community-dwelling elderly participants from the ARIC study, Shah et al. ${ }^{[3]}$ evaluated the association between LV diastolic parameters, plasma N-terminal pro-brain natriuretic peptide levels, subsequent heart failure hospitalizations and death. Concordant with prior studies, they found that 

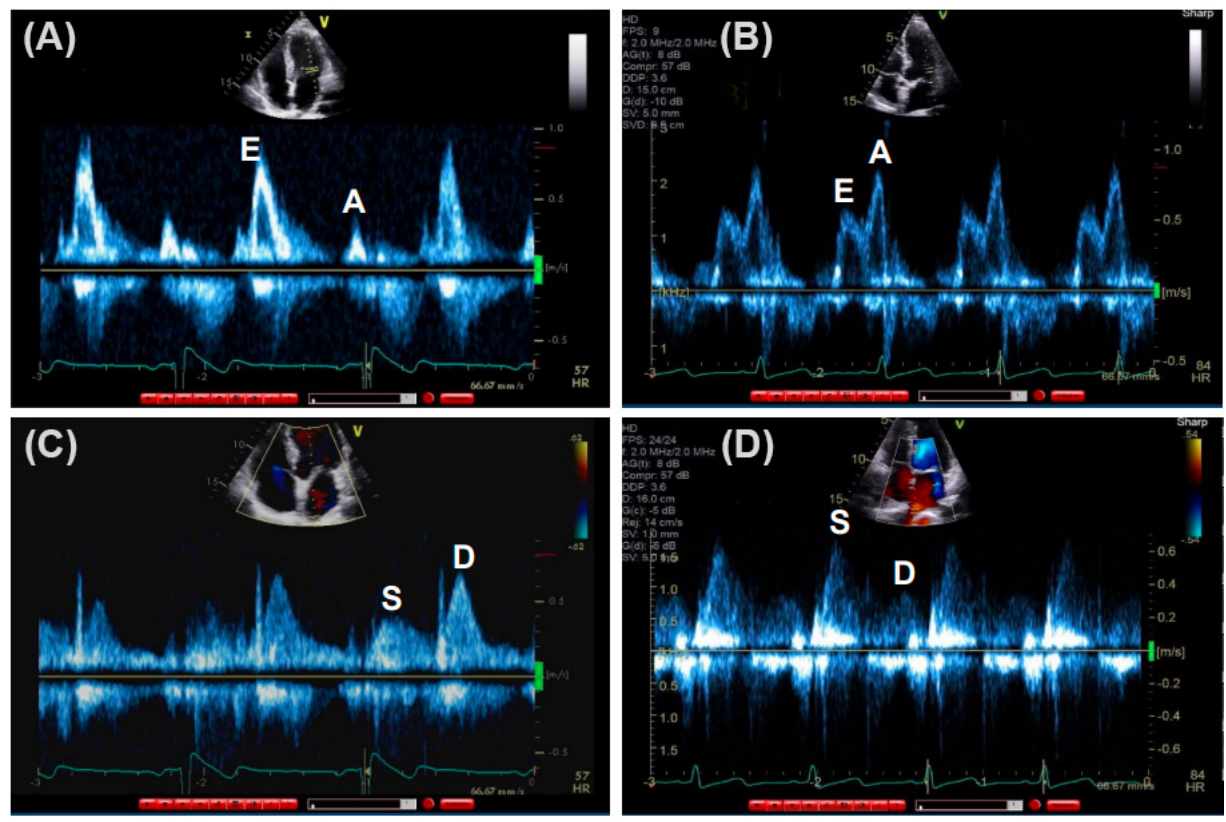

Figure 1. Pulse Doppler showing transmitral $(A$ and $B$ ) and pulmonary venous ( $C$ and $D)$ flow: $(A)$ Mitral inflow pattern $E>A$ in a young, healthy individual; (B) mitral inflow pattern $E<A$ noted in an elderly healthy individual; (C) pulmonary venous flow $S<D$ in a young, healthy individual; and (D) pulmonary venous flow $S>D$ in an elderly, healthy individual. E: Early diastolic transmitral flow velocity; A: late diastolic transmitral flow velocity; S: systolic velocity; D: diastolic velocity.
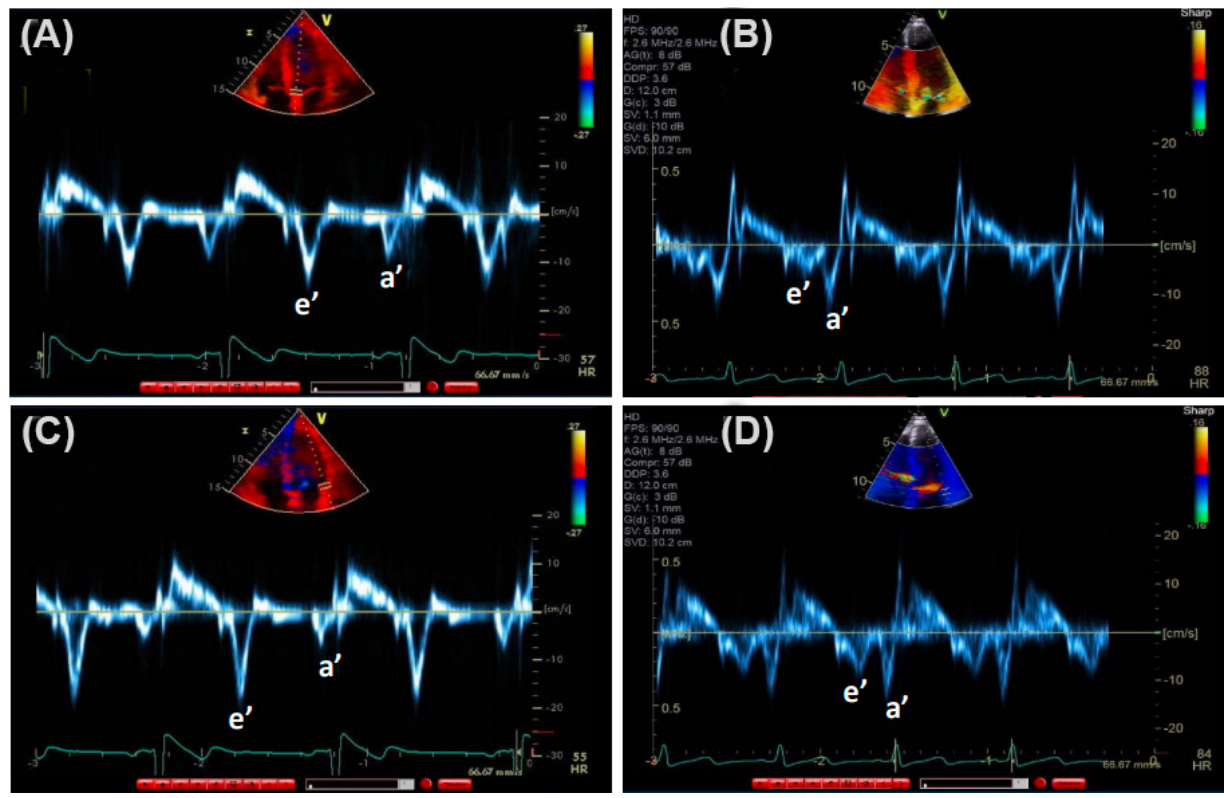

Figure 2. Tissue Doppler images showing mitral annular early $\left(e^{\prime}\right)$ and late $\left(a^{\prime}\right)$ diastolic velocities in healthy young and elderly subjects. (A) Septal e' in young, healthy individual is higher than septal e' velocity in an elderly healthy individual (B). In comparison, a' velocity is higher in the older subject. (C) Lateral $\mathrm{e}^{\prime}$ in young, healthy individual is higher than lateral $\mathrm{e}^{\prime}$ velocity in an elderly healthy individual (D). In comparison, a' velocity is higher in the older subject.

elderly individuals had lower tissue Doppler-derived mitral annular velocities (e'). Notably, the reference limits for TDI e' found in this study were lower than the general values recognized by the 2016 ASE/EACVI (European Association of Cardiovascular Imaging) guidelines. However, the reference limits for E/e' ratio 
Table 2. Summary of studies showing changes in left ventricular diastolic function with age

\begin{tabular}{|c|c|c|c|}
\hline Study & $\begin{array}{l}\text { Sample size } \\
(n)\end{array}$ & Study population & Key findings \\
\hline $\begin{array}{l}\text { Munagala et al. }{ }^{[34]} \\
(2003)\end{array}$ & 1012 & $\begin{array}{l}\text { Rochester Epidemiology } \\
\text { Project }\end{array}$ & $\begin{array}{l}\text { 1. Mitral inflow parameters: aging was associated with decrease in early transmitral flow velocity }(E) \text {, increase in atrial transmitral flow velocity }(A) \text {, } \\
\text { decrease in } E / A \text { ratio, and prolongation of } E \text { wave deceleration time } \\
\text { 2. Pulmonary venous flow: aging was associated with increase in systolic flow velocity }(S) \text {, decrease in diastolic flow velocity }(D) \text {, and increase in } \\
\text { ratio of systolic/diastolic flow velocity }(S / D) \\
\text { 3. Mitral annular velocities: aging was associated with decrease in early mitral annular velocity }\left(e^{\prime}\right) \\
\text { 4. The difference in duration between mitral inflow } A \text { wave and pulmonary venous } A_{R}\left(A_{R}-A\right) \text { did not change significantly with age }\end{array}$ \\
\hline $\begin{array}{l}\text { Caballero et al. } \\
(2015)\end{array}$ & 449 & $\begin{array}{l}\text { Doppler NORRE sub- } \\
\text { study }\end{array}$ & $\begin{array}{l}\text { 1. Mitral inflow parameters: elderly individuals (age } \geq 60 \text { years) had lower } E \text { velocity, higher A velocity, lower E/A ratio, and longer E wave } \\
\text { deceleration time } \\
\text { 2. Mitral annular velocities: } e^{\prime} \text { velocity decreased significantly with age in both genders } \\
\text { 3. The ratio of mitral } E / e^{\prime} \text { increased progressively with advancing age; however, the cut-off value of average } E / e^{\prime} \text { remained }<15\end{array}$ \\
\hline Shah et al. ${ }^{[37]}(2017)$ & 5801 & ARIC & $\begin{array}{l}\text { Elderly individuals had lower tissue Doppler-derived mitral annular early diastolic velocity (e') } \\
\text { The reference limits for ratio of E/e', were in agreement with those endorsed by the } 2016 \text { ASE/EACVI guidelines }\end{array}$ \\
\hline Lam et al. ${ }^{[38]}(2009)$ & 2042 & $\begin{array}{l}\text { Rochester Epidemiology } \\
\text { Project }\end{array}$ & Aging was associated with increase in pulmonary artery systolic pressure \\
\hline
\end{tabular}

NORRE: Normal Reference Ranges for Echocardiography; ARIC: Aatherosclerosis Risk in Communities; ASE: American Society of Echocardiography.

were in agreement with those endorsed by the guidelines ${ }^{[37]}$. Therefore, in elderly individuals, age-adjusted e' velocities are most accurate in diagnosing LV diastolic dysfunction.

In a cross-sectional study of 2042 participants undergoing echocardiography, the investigators evaluated pulmonary artery systolic pressure (PASP) from the tricuspid regurgitant (TR) velocity jet using the modified Bernoulli equation ${ }^{[38]}$. Right atrial pressure was assumed to be 5 mmHg in all individuals. The authors found that age was an independent predictor of PASP; older age was associated with an increase in PASP. In addition, increasing PASP was associated with higher mortality over a median follow-up of 9 years. Potential explanations for this age-related increase in PASP include: age-related pulmonary vascular stiffening, and LV diastolic dysfunction. This was the first population-based study that showed an age-related increase in PASP.

In summary, several conclusions can be drawn [Table 2]. First, with advancing age, there is a slowing of LV myocardial relaxation; therefore, e' velocity decreases with age. Slowing of LV relaxation also results in decreased early transmitral pressure gradient with decreased mitral E velocity, and augmentation of atrial contribution to mitral filling, i.e., A velocity. These phenomena are reflected in pulmonary venous flow profile by the increase in $\mathrm{S}$ velocity, decrease in $\mathrm{D}$ velocity, increase in S/D ratio. Second, older age is associated with an increase in PASP. Third, given its age independence, an increased $A_{R}-A$ duration (> $30 \mathrm{~ms}$ ) is a marker of elevated LV end-diastolic pressure, regardless of age ${ }^{[18]}$. Therefore, it is imperative to scrutinize multiple echocardiographic parameters in order to avoid the false-positive diagnosis of LV diastolic dysfunction amongst the elderly. 


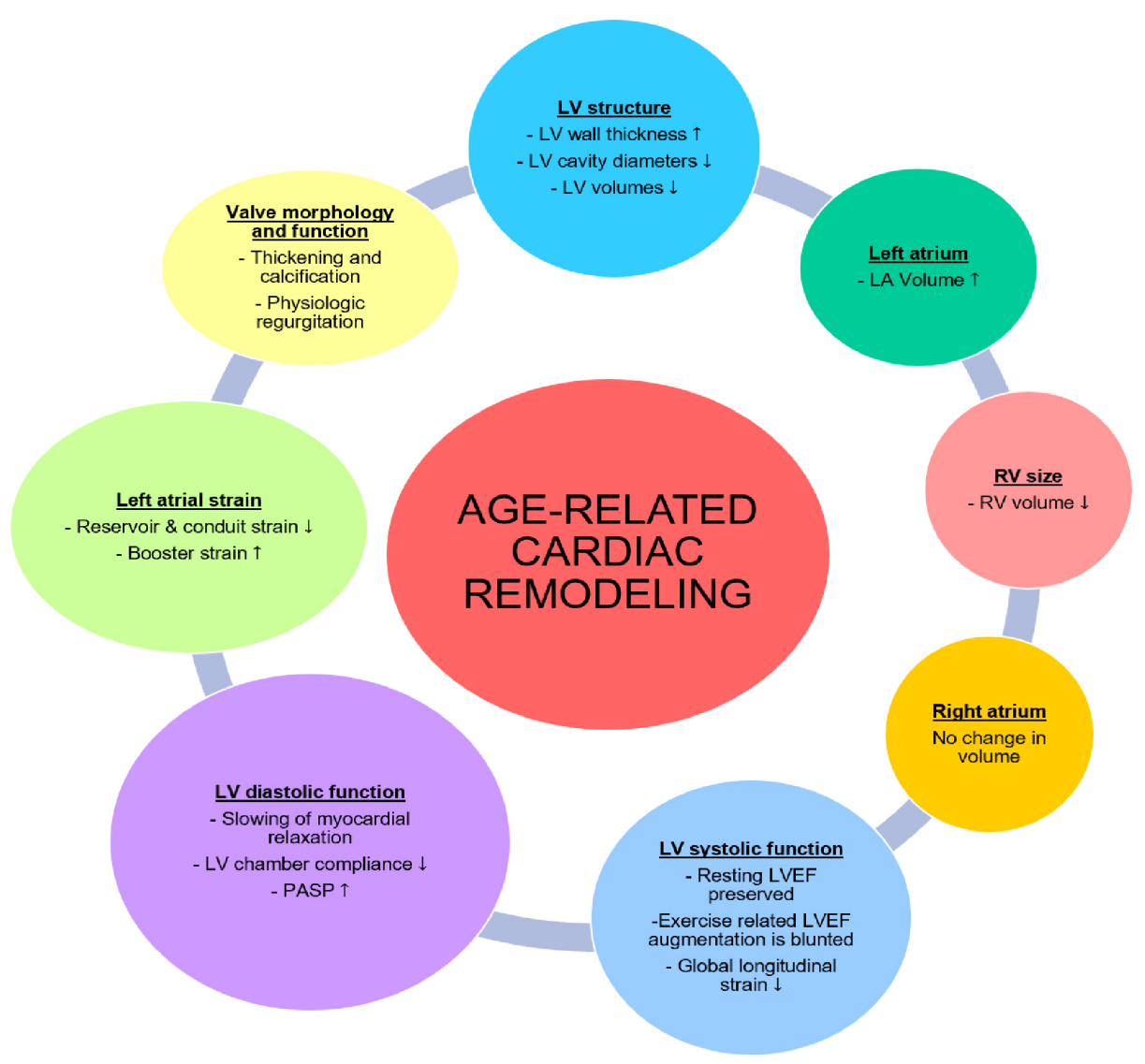

Figure 3. Overview of age related changes in cardiac structure and function. LV: Left ventricle; LA: left atrium; RV: right ventricle; LVEF: left ventricular ejection fraction; PASP: pulmonary artery systolic pressure.

\section{LEFT ATRIAL STRAIN}

Left atrial function is divided into three phases: reservoir, conduit, and booster. Reservoir function reflects the ability of the left atrium to passively receive pulmonary venous return; it occurs during LV isovolumic contraction, ejection, and isovolumic relaxation phases of the cardiac cycle. The conduit function occurs during passive transmitral flow (early diastole and mid-diastole). Lastly, the booster function occurs during late diastolic atrial contraction ${ }^{[39]}$. Left atrial strain (LAS) evaluation by speckle tracking echocardiography offers the unique opportunity to evaluate left atrial function in each of these phases. For standardization of measurement of LAS, the use of apical four-chamber view with ventricular end-diastole as time-reference has been recommended ${ }^{[40]}$. A growing body of literature shows that LAS is a promising new tool with several potential diagnostic and prognostic applications. These include non-invasive estimation of left atrial pressure, detecting the presence and severity of LV diastolic dysfunction, prognosis in patients with HFpEF, prediction of atrial fibrillation recurrence after rhythm control interventions such as electrical cardioversion or catheter ablation ${ }^{[41-46]}$. Understanding the normal reference range and impact of aging are important prerequisites for the interpretation of LAS. The WASE study group evaluated the impact of aging on left atrial function in 1765 healthy individuals using strain from 2D speckle tracking echocardiography. They found that increasing age was associated with a decrease in left atrial reservoir and conduit strain, and an increase in booster strain. The proposed mechanisms for these changes include age-related stiffening of the left atrium and compensatory augmentation of atrial contractility ${ }^{[19]}$. 
Table 3. Quantification of age-related changes in cardiac structure and function

\begin{tabular}{|c|c|c|c|c|c|c|c|c|}
\hline \multirow[t]{2}{*}{ Parameter } & \multicolumn{4}{|c|}{ Men } & \multicolumn{4}{|c|}{ Women } \\
\hline & $\begin{array}{l}\text { Young (age } \\
18-40 \\
\text { years) }\end{array}$ & $\begin{array}{l}\text { Middle age } \\
\text { (41-65 } \\
\text { years) }\end{array}$ & $\begin{array}{l}\text { Elderly (age } \\
>65 \text { years) }\end{array}$ & $\boldsymbol{P}$ & $\begin{array}{l}\text { Young (age } \\
18-40 \\
\text { years) }\end{array}$ & $\begin{array}{l}\text { Middle age } \\
\text { (41-65 } \\
\text { years) }\end{array}$ & $\begin{array}{l}\text { Elderly (age } \\
>65 \text { years) }\end{array}$ & $\mathbf{P}$ \\
\hline 3D LVEDV (mL) & $142.9 \pm 33.5$ & $128.9 \pm 29.8$ & $121.9 \pm 28.4$ & $\begin{array}{l}P< \\
0.05^{*}\end{array}$ & $111.5 \pm 23.8$ & $108.4 \pm 21.9$ & $97.4 \pm 22.7$ & $\begin{array}{l}P< \\
0.05^{\star}\end{array}$ \\
\hline 3D LVEDVi $\left(\mathrm{mL} / \mathrm{m}^{2}\right)$ & $74.9 \pm 14.4$ & $67.6 \pm 13.7$ & $66.1 \pm 13.6$ & $\begin{array}{l}P< \\
0.05^{*}\end{array}$ & $67.7 \pm 11.5$ & $64.5 \pm 11.9$ & $60.1 \pm 11.9$ & $\begin{array}{l}P< \\
0.05\end{array}$ \\
\hline 3D LVESV (mL) & $58.2 \pm 16.5$ & $51.3 \pm 13.7$ & $47.7 \pm 14.3$ & $\begin{array}{l}P< \\
0.05^{*}\end{array}$ & $42.7 \pm 11.1$ & $40.9 \pm 10.1$ & $36.5 \pm 10.1$ & $\begin{array}{l}P< \\
0.05^{*}\end{array}$ \\
\hline 3D LVESVi $\left(\mathrm{mL} / \mathrm{m}^{2}\right)$ & $30.5 \pm 7.3$ & $26.9 \pm 6.3$ & $25.8 \pm 6.9$ & $\begin{array}{l}P< \\
0.05^{*}\end{array}$ & $25.9 \pm 5.6$ & $24.3 \pm 5.6$ & $22.4 \pm 5.6$ & $\begin{array}{l}P< \\
0.05\end{array}$ \\
\hline $\begin{array}{l}\text { 3D maximum LAVi } \\
\left(\mathrm{mL} / \mathrm{m}^{2}\right)\end{array}$ & $26.5 \pm 6.2$ & $28.7 \pm 7.5$ & $30.5 \pm 7.5$ & $\begin{array}{l}P< \\
0.05^{*}\end{array}$ & $26.8 \pm 5.8$ & $27.9 \pm 6.8$ & $30.2 \pm 7.4$ & $\begin{array}{l}P< \\
0.05^{\star}\end{array}$ \\
\hline $\begin{array}{l}\text { Mitral annular velocity: } \\
\text { septal } \mathrm{E}^{\prime} \text { (averages value in } \\
\mathrm{cm} / \mathrm{s} \text { ) }\end{array}$ & 11.2 & 8.72 & 7.41 & $\begin{array}{l}P< \\
0.01\end{array}$ & 11.94 & 9.06 & 6.65 & $\begin{array}{l}P< \\
0.01\end{array}$ \\
\hline $\begin{array}{l}\text { Mitral annular velocity: } \\
\text { lateral } \mathrm{E}^{\prime} \text { (average values in } \\
\mathrm{cm} / \mathrm{s} \text { ) }\end{array}$ & 15.44 & 11.62 & 9.58 & $\begin{array}{l}P< \\
0.01\end{array}$ & 15.89 & 11.71 & 8.92 & $\begin{array}{l}P< \\
0.01\end{array}$ \\
\hline
\end{tabular}

This table presents insights regarding the quantification of age-related changes in cardiac structure and function from the WASE studies ${ }^{[19,51,52]}$. *By 3-way analysis of variance. WASE: World Alliance Societies of Echocardiography; 3D: three-dimensional; LV: left ventricle; LVEDV: left ventricular end diastolic volume; LVESV: left ventricular end systolic volume; LVEDVi: left ventricular end diastolic volume indexed to body surface area; LVESVi: left ventricular end systolic volume indexed to body surface area; LAVi: left atrial volume indexed to body-surface-area.

\section{VALVE MORPHOLOGY AND FUNCTION}

Common patterns of valve abnormalities reported with advancing age include thickening and calcification of aortic and mitral valves, and trivial to mild physiologic regurgitation. We discuss here a few studies that illustrated these findings.

In an autopsy study of 200 hearts, those with age $>60$ years had significant thickening of the aortic and mitral valves compared with subjects $<20$ years of age ${ }^{[47]}$. These findings were confirmed in cross-sectional analyses of healthy participants undergoing echocardiography. A study of 5201 individuals aged $\geq 65$ years from the Cardiovascular Healthy Study (CHS) showed that the prevalence of aortic valve sclerosis was $26 \%$. This study also identified increasing age as an independent risk factor for the development of aortic valve sclerosis ${ }^{[48]}$. Another study of 3929 elderly participants ( $76 \pm 5$ years) from the CHS showed that the prevalence of mitral annular calcification was $42 \%$, aortic annular calcification $44 \%$, and aortic valve sclerosis $54 \%^{[49]}$.

With respect to valvular function, Klein et al. ${ }^{[50]}$ studied the prevalence of valve regurgitation amongst healthy volunteers using color flow Doppler echocardiography. Among older participants ( $>50$ years), they reported a $58 \%$ prevalence of trivial to mild mitral regurgitation, $74 \%$ prevalence of tricuspid regurgitation, $11 \%$ prevalence of aortic regurgitation, and $41 \%$ prevalence of pulmonary regurgitation. In comparison, mitral regurgitation was present in $39 \%$ of subjects $<50$ years old, with $57 \%$ having tricuspid regurgitation, $22 \%$ pulmonary regurgitation, and none with aortic regurgitation in the same age group. This study showed that trivial to mild valve regurgitation is common amongst older individuals, and the prevalence increases with advancing age $e^{[50]}$. 


\section{CONCLUSION}

Healthy aging is associated with significant alterations in cardiac chamber size and function ${ }^{[5,52]}$ [Figure 3, Table 3]. Further research is needed to delineate age-related reference limits for various echocardiographic parameters.

\section{DECLARATIONS}

Authors' contributions

Conceived and wrote the paper: Agrawal T, Nagueh SF

\section{Availability of data and materials}

Not applicable.

\section{Financial support and sponsorship}

None.

\section{Conflicts of interest}

Both authors declared that there are no conflicts of interest.

\section{Ethical approval and consent to participate}

Not applicable.

\section{Consent for publication}

Not applicable.

\section{Copyright}

(c) The Author(s) 2022.

\section{REFERENCES}

1. Roth GA, Mensah GA, Johnson CO, et al; GBD-NHLBI-JACC Global Burden of Cardiovascular Diseases Writing Group. Global Burden of Cardiovascular Diseases and Risk Factors, 1990-2019: update from the GBD 2019 study. J Am Coll Cardiol 2020;76:29823021. DOI PubMed PMC

2. Kitzman DW, Scholz DG, Hagen PT, Ilstrup DM, Edwards WD. Age-related changes in normal human hearts during the first 10 decades of life. Part II (Maturity): a quantitative anatomic study of 765 specimens from subjects 20 to 99 years old. Mayo Clin Proc 1988;63:137-46. DOI PubMed

3. Gardin JM, Henry WL, Savage DD, Ware JH, Burn C, Borer JS. Echocardiographic measurements in normal subjects: evaluation of an adult population without clinically apparent heart disease. J Clin Ultrasound 1979;7:439-47. DOI PubMed

4. Levy D, Anderson KM, Savage DD, Kannel WB, Christiansen JC, Castelli WP. Echocardiographically detected left ventricular hypertrophy: prevalence and risk factors. The Framingham Heart Study. Ann Intern Med 1988;108:7-13. DOI PubMed

5. Devereux RB, Reichek N. Echocardiographic determination of left ventricular mass in man. Anatomic validation of the method. Circulation 1977;55:613-8. DOI PubMed

6. Lieb W, Xanthakis V, Sullivan LM, et al. Longitudinal tracking of left ventricular mass over the adult life course: clinical correlates of short- and long-term change in the framingham offspring study. Circulation 2009;119:3085-92. DOI PubMed PMC

7. Cheng S, Xanthakis V, Sullivan LM, et al. Correlates of echocardiographic indices of cardiac remodeling over the adult life course: longitudinal observations from the Framingham Heart Study. Circulation 2010;122:570-8. DOI PubMed PMC

8. Olivetti G, Melissari M, Capasso JM, Anversa P. Cardiomyopathy of the aging human heart. Myocyte loss and reactive cellular hypertrophy. Circ Res 1991;68:1560-8. DOI PubMed

9. Kaku K, Takeuchi M, Otani K, et al. Age- and gender-dependency of left ventricular geometry assessed with real-time threedimensional transthoracic echocardiography. J Am Soc Echocardiogr 2011;24:541-7. DOI PubMed

10. Støylen A, Mølmen HE, Dalen H. Importance of length and external diameter in left ventricular geometry. Normal values from the HUNT Study. Open Heart 2016;3:e000465. DOI PubMed PMC

11. Chahal NS, Lim TK, Jain P, Chambers JC, Kooner JS, Senior R. Population-based reference values for 3D echocardiographic LV volumes and ejection fraction. JACC Cardiovasc Imaging 2012;5:1191-7. DOI PubMed

12. Kou S, Caballero L, Dulgheru R, et al. Echocardiographic reference ranges for normal cardiac chamber size: results from the NORRE study. Eur Heart J Cardiovasc Imaging 2014;15:680-90. DOI PubMed PMC 
13. Lang RM, Badano LP, Mor-Avi V, et al. Recommendations for cardiac chamber quantification by echocardiography in adults: an update from the American Society of Echocardiography and the European Association of Cardiovascular Imaging. J Am Soc Echocardiogr 2015;28:1-39.e14. DOI PubMed

14. Lancellotti P, Badano LP, Lang RM, et al. Normal Reference Ranges for Echocardiography: rationale, study design, and methodology (NORRE Study). Eur Heart J Cardiovasc Imaging 2013;14:303-8. DOI PubMed

15. Daimon M, Watanabe H, Abe Y, et al; JAMP Study Investigators. Normal values of echocardiographic parameters in relation to age in a healthy Japanese population: the JAMP study. Circ J 2008;72:1859-66. DOI PubMed

16. Fukuda S, Watanabe H, Daimon M, et al. Normal values of real-time 3-dimensional echocardiographic parameters in a healthy Japanese population: the JAMP-3D Study. Circ J 2012;76:1177-81. DOI PubMed

17. Bernard A, Addetia K, Dulgheru R, et al. 3D echocardiographic reference ranges for normal left ventricular volumes and strain: results from the EACVI NORRE study. Eur Heart J Cardiovasc Imaging 2017;18:475-83. DOI PubMed

18. Nagueh SF, Smiseth OA, Appleton CP, et al. Recommendations for the evaluation of left ventricular diastolic function by echocardiography: an update from the American Society of Echocardiography and the European Association of Cardiovascular Imaging. J Am Soc Echocardiogr 2016;29:277-314. DOI PubMed

19. Singh A, Carvalho Singulane C, Miyoshi T, et al; WASE Investigators. Normal values of left atrial size and function and the impact of age: results of the World Alliance Societies of Echocardiography Study. J Am Soc Echocardiogr 2021. DOI PubMed

20. Maffessanti F, Muraru D, Esposito R, et al. Age-, body size-, and sex-specific reference values for right ventricular volumes and ejection fraction by three-dimensional echocardiography: a multicenter echocardiographic study in 507 healthy volunteers. Circ Cardiovasc Imaging 2013;6:700-10. DOI PubMed

21. Fiechter M, Fuchs TA, Gebhard C, et al. Age-related normal structural and functional ventricular values in cardiac function assessed by magnetic resonance. BMC Med Imaging 2013;13:6. DOI PubMed PMC

22. Soulat-Dufour L, Addetia K, Miyoshi T, et al; WASE Investigators. Normal values of right atrial size and function according to age, sex, and ethnicity: results of the World Alliance Societies of Echocardiography Study. J Am Soc Echocardiogr 2021;34:286-300. DOI PubMed

23. Gerstenblith G, Frederiksen J, Yin FC, Fortuin NJ, Lakatta EG, Weisfeldt ML. Echocardiographic assessment of a normal adult aging population. Circulation 1977;56:273-8. DOI PubMed

24. Vriz O, Pirisi M, Habib E, et al. Age related structural and functional changes in left ventricular performance in healthy subjects: a $2 \mathrm{D}$ echocardiographic study. Int J Cardiovasc Imaging 2019;35:2037-47. DOI PubMed

25. Hung CL, Gonçalves A, Shah AM, Cheng S, Kitzman D, Solomon SD. Age- and sex-related influences on left ventricular mechanics in elderly individuals free of prevalent heart failure: the ARIC Study (Atherosclerosis Risk in Communities). Circ Cardiovasc Imaging 2017; 10:e004510. DOI PubMed PMC

26. Port S, Cobb FR, Coleman RE, Jones RH. Effect of age on the response of the left ventricular ejection fraction to exercise. $N$ Engl $J$ Med 1980;303:1133-7. DOI PubMed

27. D'Elia N, Caselli S, Kosmala W, et al. Normal global longitudinal strain: an individual patient meta-analysis. JACC Cardiovasc Imaging 2020;13:167-9. DOI PubMed

28. Owan TE, Hodge DO, Herges RM, Jacobsen SJ, Roger VL, Redfield MM. Trends in prevalence and outcome of heart failure with preserved ejection fraction. N Engl J Med 2006;355:251-9. DOI PubMed

29. Paulus WJ, Tschöpe C, Sanderson JE, et al. How to diagnose diastolic heart failure: a consensus statement on the diagnosis of heart failure with normal left ventricular ejection fraction by the Heart Failure and Echocardiography Associations of the European Society of Cardiology. Eur Heart J 2007;28:2539-50. DOI PubMed

30. Kitzman DW, Gardin JM, Gottdiener JS, et al. Importance of heart failure with preserved systolic function in patients $\geq 65$ years of age. Am J Cardiol 2001;87:413-9. DOI

31. Vasan RS, Benjamin EJ, Levy D. Prevalence, clinical features and prognosis of diastolic heart failure: An epidemiologic perspective. $J$ Am Coll Cardiol 1995;26:1565-74. DOI PubMed

32. Benjamin EJ, Levy D, Anderson KM, et al. Determinants of Doppler indexes of left ventricular diastolic function in normal subjects (the Framingham heart study). Am J Cardiol 1992;70:508-15. DOI PubMed

33. Klein AL, Burstow DJ, Tajik AJ, Zachariah PK, Bailey KR, Seward JB. Effects of age on left ventricular dimensions and filling dynamics in 117 normal persons. Mayo Clinic Proceedings 1994;69:212-24. DOI PubMed

34. Munagala VK, Jacobsen SJ, Mahoney DW, Rodeheffer RJ, Bailey KR, Redfield MM. Association of newer diastolic function parameters with age in healthy subjects: a population-based study. J Am Soc Echocardiogr 2003;16:1049-56. DOI PubMed

35. Nagueh SF, Appleton CP, Gillebert TC, et al. Recommendations for the evaluation of left ventricular diastolic function by echocardiography. J Am Soc Echocardiogr 2009;22:107-33. DOI PubMed

36. Caballero L, Kou S, Dulgheru R, et al. Echocardiographic reference ranges for normal cardiac Doppler data: results from the NORRE Study. Eur Heart J Cardiovasc Imaging 2015;16:1031-41. DOI PubMed

37. Shah AM, Claggett B, Kitzman D, et al. Contemporary assessment of left ventricular diastolic function in older adults: the Atherosclerosis Risk in Communities Study. Circulation 2017;135:426-39. DOI PubMed PMC

38. Lam CS, Borlaug BA, Kane GC, Enders FT, Rodeheffer RJ, Redfield MM. Age-associated increases in pulmonary artery systolic pressure in the general population. Circulation 2009;119:2663-70. DOI PubMed PMC

39. Blume GG, Mcleod CJ, Barnes ME, et al. Left atrial function: physiology, assessment, and clinical implications. Eur J Echocardiogr 2011;12:421-30. DOI PubMed

40. Badano LP, Kolias TJ, Muraru D, et al; Industry representatives; Reviewers: this document was reviewed by members of the 2016- 
2018 EACVI Scientific Documents Committee. Standardization of left atrial, right ventricular, and right atrial deformation imaging using two-dimensional speckle tracking echocardiography: a consensus document of the EACVI/ASE/Industry Task Force to standardize deformation imaging. Eur Heart J Cardiovasc Imaging 2018;19:591-600. DOI PubMed

41. Wakami K, Ohte N, Asada K, et al. Correlation between left ventricular end-diastolic pressure and peak left atrial wall strain during left ventricular systole. J Am Soc Echocardiogr 2009;22:847-51. DOI PubMed

42. Freed BH, Daruwalla V, Cheng JY, et al. Prognostic utility and clinical significance of cardiac mechanics in heart failure with preserved ejection fraction: importance of left atrial strain. Circ Cardiovasc Imaging 2016;9:e003754. DOI PubMed PMC

43. Kuppahally SS, Akoum N, Burgon NS, et al. Left atrial strain and strain rate in patients with paroxysmal and persistent atrial fibrillation: relationship to left atrial structural remodeling detected by delayed-enhancement MRI. Circ Cardiovasc Imaging 2010;3:231-9. DOI PubMed

44. Yasuda R, Murata M, Roberts R, et al. Left atrial strain is a powerful predictor of atrial fibrillation recurrence after catheter ablation: study of a heterogeneous population with sinus rhythm or atrial fibrillation. Eur Heart J Cardiovasc Imaging 2015;16:1008-14. DOI PubMed

45. Moreno-Ruiz LA, Madrid-Miller A, Martínez-Flores JE, et al. Left atrial longitudinal strain by speckle tracking as independent predictor of recurrence after electrical cardioversion in persistent and long standing persistent non-valvular atrial fibrillation. Int $J$ Cardiovasc Imaging 2019;35:1587-96. DOI PubMed PMC

46. Kim J, Yum B, Palumbo MC, et al. Left atrial strain impairment precedes geometric remodeling as a marker of post-myocardial infarction diastolic dysfunction. JACC Cardiovasc Imaging 2020;13:2099-113. DOI PubMed PMC

47. Sahasakul Y, Edwards WD, Naessens JM, Tajik A. Age-related changes in aortic and mitral valve thickness: implications for twodimensional echocardiography based on an autopsy study of 200 normal human hearts. Am J Cardiol 1988;62:424-30. DOI PubMed

48. Stewart BF, Siscovick D, Lind BK, et al. Clinical factors associated with calcific aortic valve disease. Cardiovascular Health Study. $J$ Am Coll Cardiol 1997;29:630-4. DOI PubMed

49. Barasch E, Gottdiener JS, Larsen EK, Chaves PH, Newman AB, Manolio TA. Clinical significance of calcification of the fibrous skeleton of the heart and aortosclerosis in community dwelling elderly. The Cardiovascular Health Study (CHS). Am Heart $J$ 2006;151:39-47. DOI PubMed

50. Klein AL, Burstow DJ, Tajik AJ, et al. Age-related prevalence of valvular regurgitation in normal subjects: a comprehensive color flow examination of 118, volunteers. J Am Soc Echocardiogr 1990;3:54-63. DOI PubMed

51. Addetia K, Miyoshi T, Amuthan V, et al; WASE Investigators. Normal values of left ventricular size and function on threedimensional echocardiography: results of the World Alliance Societies of Echocardiography Study. J Am Soc Echocardiogr 2021. DOI PubMed

52. Miyoshi T, Addetia K, Citro R, et al; WASE Investigators. Left ventricular diastolic function in healthy adult individuals: results of the World Alliance Societies of Echocardiography Normal Values Study. J Am Soc Echocardiogr 2020;33:1223-33. DOI PubMed 